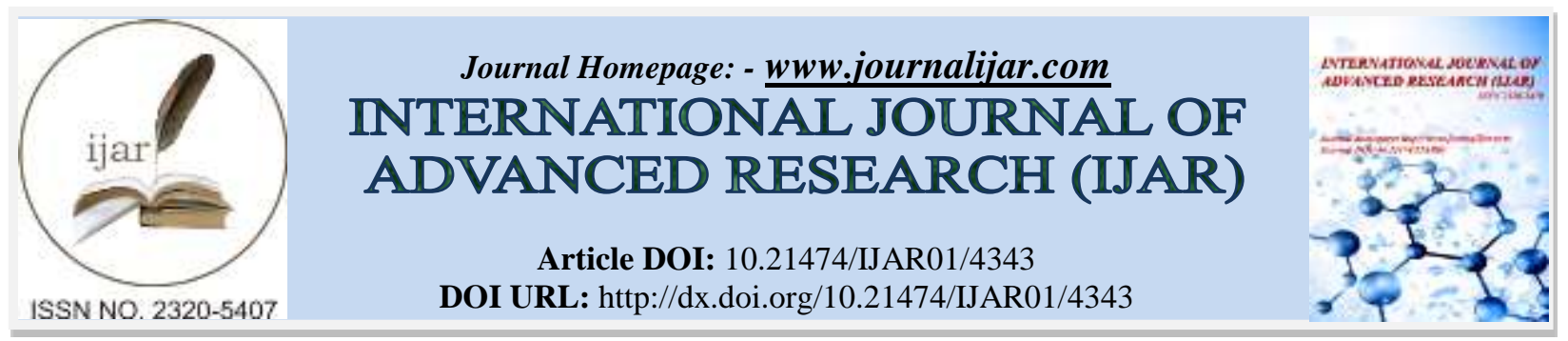

RESEARCH ARTICLE

\title{
SOCIAL BEHAVIOUR OF SECONDARY STUDENTS: WITH REFERENCE TO PARTICIPATION IN COMPETITIVE SPORTSMd.
}

\author{
Monaim Hossan Chowdhury ${ }^{1}$ and Dr. Yuwraj Shrivastava ${ }^{2}$. \\ 1. M.Phil. Student, Dr. C.V. Raman University, Kota Bilaspur C.G. \\ 2. Assistant Professor, Department of Physical Education, Dr. C.V. Raman University, Kota Bilaspur C.G.
}

\section{Manuscript Info}

Manuscript History

Received: 16 March 2017

Final Accepted: 19 April

2017Published: May 2017

Key words:-

Social behaviour, participation in sports, secondary students

\section{Abstract}

In the present study social behaviour among secondary students was compared on the basis of their participation in competitive sports. 50 player boys (Ave. age 16.97 yrs) and 50 non player boys (Ave. age $17.11 \mathrm{yrs}$ ) were selected from secondary schools of Bilaspur city. The criterion for selection of player boys was participation in district/state level tournaments in any sporting event. Random sampling method was used for selection of sample in the present study. To assess social behaviour, Social Skills Problem Behaviour Checklist prepared by Madhu Mathur and Saroj Arora (2005) was used. It was found that problematic social behaviour was significantly in more magnitude in non-player boys as compared to player boys studying in secondary schools. It was concluded that participation in sports emerged as good medium to enhance social behaviour of secondary students.

Copy Right, IJAR, 2016,. All rights reserved.

\section{Introduction:-}

Social psychology is the scientific study of how people's thoughts, feelings, and behaviours are influenced by the actual, imagined, or implied presence of others (Allport, 1965). In psychology, social behaviour is referred to human behaviour. It covers behaviours ranging from physical to emotional that we communicate in and also the way we are influenced by ethics, attitudes, genetics and culture etc. In the present study social behaviour has been taken in terms of social skills such as presentation skills, interaction skills, conversation skills, social integration, attitude towards other students and attitude towards adults respectively.

It has also been propagated that participation in sports is an excellent medium for overall development of human [Verner et al. (2010), Gahlawat and Gahlawat (2012), Omran et al. (2014), Mittal (2014)] Hence the present study has been carried out to compare social behaviour between secondary student athletes and non-athletes.

\section{Hypothesis:-}

It was hypothesized that "Significant difference will be observed in social behaviour of player and non player boys studying in secondary schools".

\section{Methodology:-}

The following methodological steps were taken in order to conduct the present study. 


\section{Sample:-}

For present study, 50 player boys (Ave. age $16.97 \mathrm{yrs}$ ) and 50 non player boys (Ave. age 17.11 yrs) were selected from secondary schools of Bilaspur city. The criterion for selection of player boys was participation in district/state level tournaments in any sporting event. Random sampling method was used for selection of sample in the present study.

\section{Tools:-}

\section{Social Skills Problem Behaviour Checklist:-}

To assess social behaviour, Social Skills Problem Behaviour Checklist prepared by Madhu Mathur and Saroj Arora (2005) was used. This 06 dimensional social skills problem behaviour checklist consists of 62 statements. The dimensions are Presentation Skills, Interaction Skills, Conversation Skills, Social Integration, Attitude towards other students and Attitude towards Adults respectively. The interpretation of raw scores is such that higher the scores, more is the magnitude of social behavioural problems. This checklist is highly reliable and valid.

\section{Procedure:-}

After establishing a good rapport with the subjects they were assured that their responses and their identities will be kept under strict confidence and will not be disclosed anywhere. Thus, they are free to give their answers comfortably and honestly whatever they felt. In this way, subjects were encouraged to give their proper co-operation during the testing. The printed instructions given on the cover page of the Social Skills Problem Behaviour Checklist was explained to the subjects before the administration and then asked to give their response. After this, the scoring was completed according to the scoring system prescribed by the author of this checklist. After scoring, the data was tabulated according to their groups. Independent sample ' $t$ ' test was used to analyse the data. Results shown in table 1 .

\section{Result and Discussion:-}

Table 1:- Comparison of Social Behaviour between Player and Non-player Boys.

\begin{tabular}{|c|c|c|c|c|c|c|}
\hline \multirow[t]{2}{*}{ Groups } & \multicolumn{2}{|l|}{$\begin{array}{l}\text { Player } \\
(\mathrm{N}=50)\end{array}$} & \multicolumn{2}{|c|}{$\begin{array}{ll}\text { Non } & \text { Player } \\
(\mathrm{N}=50) & \end{array}$} & \multirow[t]{2}{*}{$\begin{array}{l}\text { Mean } \\
\text {.Diff }\end{array}$} & \multirow[t]{2}{*}{$' t^{6}$} \\
\hline & Mean & .S.D & Mean & .S.D & & \\
\hline Social behaviour & 102.22 & 26.48 & 113.84 & 19.80 & 11.62 & $2.48 *$ \\
\hline
\end{tabular}

Significant at .05 level **

A perusal of entries reported in table 1 indicate that problematic social behaviour was found to be significantly in more magnitude in non-player boys $(M=113.84)$ as compared to player boys $(M=102.22)$ studying in secondary schools. The results are interpreted as lower the score, better is social behaviour. This fact was also verified statistically as calculated $\mathrm{t}=2.48$ was found to be statistically significant at .05 level. It is well known fact that sports teaches virtues. Through participation in sports one learns cooperation, cooperativeness, communication, emotional control etc. Earlier Mehri et al. (2012) scientifically reported that participation in competitive sports is also beneficial for physical, emotional, and mental health promotion. Since social behaviour comes from all these parameters hence the results are not surprising.

\section{Conclusion:-}

On the basis of results it can be concluded that participation in sports emerged as good medium to enhance social behaviour of secondary students.

\section{References:-}

1. Allport, G. W (1965). The historical background of social psychology. In Lindzey, G; Aronson, E. The Handbook of Social Psychology. New York: McGraw Hill. p. 5.

2. Gahlawat, O.P. and Gahlawat, P. (2012). A Comparative Study of Player and Non- Player Students in Relation to Mental Health. Journal of Exercise Science and Physiotherapy, Vol. 8, No. 1: 43-47.

3. Mehri, A., Maleki, B. and Sedghi, K.S. (2014). The relationship between mental health and emotional intelligence among athlete and non-athlete male students. Journal of Health and Hygiene, Vol. 2, No. 4, pp. 6484.

4. Mittal, Bhavna (2014). A Comparative Study on the Adjustment of Player and Non-Player College Level Female Students. International Journal of Health, Sports and Physical Education Vol. 2, No. 2: 13 - 15. 
5. Omran, Z.H.N., Ghasemi, A., Zahedmanesh, F. and Golchin, E. (2014). The difference of Social development between female athletes and non-athletes students in the first year of high school in Islamshahr. International Journal of Sport Studies. Vol., 4 (2), 229-232.

6. Verner et al. (2010), Gahlawat and Gahlawat (2012), Omran et al. (2014), Mittal (2014)]

7. Verner, M.; Conzelmann, A.; Lehnert, K.; Seiler, R.; Wassmer, A. and Rammsayer, T. (2010). Subjective stress in female elite athletes and non-athletes: Evidence from cortisol analyses. European Journal of .Psychology, Vol. 6, No. 10 